\title{
Changes of Retina Are Not Involved in the Genesis of Visual Hallucinations in Parkinson's Disease
}

\author{
Aleš Kopal, ${ }^{1}$ Eva Mejzlíková, ${ }^{2}$ Jana Lízrová Preiningerová, ${ }^{3}$ David Brebera, ${ }^{4}$ \\ Olga Ulmanová, ${ }^{3}$ Edvard Ehler, ${ }^{1}$ and Jan Roth ${ }^{3}$ \\ ${ }^{1}$ Department of Neurology, Regional Hospital Pardubice, Kyjevska 44, 53203 Pardubice, Czech Republic \\ ${ }^{2}$ Department of Ophthalmology, Regional Hospital Pardubice, Kyjevska 44, 53203 Pardubice, Czech Republic \\ ${ }^{3}$ Department of Neurology and Center of Clinical Neuroscience, Charles University in Prague, 1st Faculty of Medicine and \\ General University Hospital in Prague, Katerinska 30, 12821 Prague, Czech Republic \\ ${ }^{4}$ Department of Mathematics and Quantitative Methods, Faculty of Economics and Administration, University of Pardubice, \\ Studentska 95, 53210 Pardubice, Czech Republic
}

Correspondence should be addressed to Aleš Kopal; ales.kopal@seznam.cz

Received 23 October 2014; Accepted 29 December 2014

Academic Editor: Marjan Jahanshahi

Copyright (C) 2015 Aleš Kopal et al. This is an open access article distributed under the Creative Commons Attribution License, which permits unrestricted use, distribution, and reproduction in any medium, provided the original work is properly cited.

Parkinson's disease (PD) is characterized by motor and nonmotor symptoms. Nonmotor symptoms include primarily visual hallucinations (VH). The aim of our study was to establish whether patients with PD and visual hallucinations (PDH+) have structural changes of retina detected by an optical coherence tomography (OCT) in comparison with PD patients without visual hallucinations (PDH-). We examined 52 PD patients (18 with VH, 34 without $\mathrm{VH}$ ) and 15 age and sex matched healthy controls. Retinal nerve fiber layer (RNFL) thickness and macular thickness and volume were assessed by OCT. Functional impairment of retina was assessed using $2.5 \%$ contrast sensitivity test. For OCT outcomes we analyzed $15 \mathrm{PDH}+$ and $15 \mathrm{PDH}-$ subjects matched for age, gender, and PD duration. For contrast sensitivity we analyzed 8 pairs of patients matched for age, gender, and visual acuity. There was no significant difference in RNFL thickness and macular thickness and macular volume between 15 PDH+ and 15 PDHsubjects, and also between a group of $44 \mathrm{PD}$ patients (both PDH+ and PDH-) and 15 age and gender matched healthy controls. No significant difference was found for $2.5 \%$ contrast sensitivity test values between PDH+ and PDH- subjects. Therefore we conclude that functional and structural changes in retina play no role in genesis of $\mathrm{VH}$ in PD.

\section{Introduction}

Parkinson's disease (PD) is a slowly progressive neurodegenerative disorder characterized by numerous motor and nonmotor symptoms. Cardinal motor symptoms (bradykinesia, rigidity, rest tremor, and postural instability) develop due to dopaminergic deficiency in striatum. Degree of dopaminergic deficiency correlates with disease duration and progression of motor symptoms [1]. Nonmotor symptoms include vegetative dysfunction, sleep disorders, depression, cognitive dysfunctions, psychosis, and sensory disturbances. Visual hallucinations $(\mathrm{VH})$ are typical feature of psychosis in PD. VH develop in $30-60 \%$ of PD patients $[2,3]$ and their prevalence increases with disease progression [4].

Pathophysiology of hallucinations in PD has not been fully clarified yet. VH may be induced by dopaminergic drugs but may also develop as a natural symptom of PD. In pathogenesis of hallucinations, both peripheral (retinal) and central (association cortex) changes have been discussed $[2,4]$.

Disturbances of retina, where dopaminergic amacrine cells are located, have been considered [5]. Amacrine cells influence synapses in all retinal layers and are therefore involved in photopic and scotopic vision [6]. Retinal dysfunction may influence image creation and cause its disturbances [5-8]. Morphological changes of multiple cell layers in retina may follow. Changes in retina can be imaged by optical coherence tomography (OCT), which is a noninvasive technique that captures retinal structures in micrometer resolution.

We hypothesized that, as a consequence of functional and structural changes of dopaminergic amacrine cells in retina, there is a significant reduction of RNFL thickness 
TABle 1: Demographic data.

\begin{tabular}{|c|c|c|c|c|}
\hline & \multicolumn{2}{|c|}{$\mathrm{PDH}+$} & \multicolumn{2}{|c|}{ PDH- } \\
\hline & Men & Women & Men & Women \\
\hline & $N=10$ & $N=8$ & $N=18$ & $N=16$ \\
\hline Mean age (SD) & $69(9.6)$ & $74.6(5.7)$ & $67.6(8.9)$ & $68.3(7.9)$ \\
\hline Range (years) & $52-83$ & $65-81$ & $43-80$ & 49-79 \\
\hline Mean disease duration (SD) & $10.2(4.2)$ & $10.1(5.1)$ & $6.7(3.5)$ & $8.2(4.4)$ \\
\hline Range (years) & $4-18$ & $3-19$ & $2-13$ & $3-16$ \\
\hline
\end{tabular}

PDH+: group of Parkinson's disease with hallucinations; PDH-: group of Parkinson’s disease without hallucinations; SD: standard deviation.

and macular thickness and volume in PD patients with hallucinations (PDH+) compared to PD patients without hallucinations (PDH-). Such result would support the role of retinal involvement in genesis of $\mathrm{VH}$.

\section{Subjects and Methods}

All patients with diagnosis of PD that attended Clinic of Neurology in a Regional Hospital Pardubice from May 2011 to May 2012 were preselected for the study. Only evennumbered subjects from the alphabetically ordered name list of 164 patients were invited to join the study. 71 subjects were included in the study as 11 subjects refused to participate.

The study was approved by a local ethical committee and all subjects gave informed consent prior to the enrollment to the study.

All subjects fulfilled the diagnostic criteria of PD according to the United Kingdom Parkinson's Disease Society Brain Bank [9]. Only subjects with disease onset after 40 years of age were included in the study. Exclusion criteria were history of central nervous system disorder other than PD, inflammatory disorder of the eye in the last 3 months, and history of optic neuritis or vitreoretinal pathology (including glaucoma, diabetic retinopathy, and age-related macular degeneration). Altogether 19 subjects had to be excluded and remaining 52 subjects (18 patients with $\mathrm{VH}$ and 34 without $\mathrm{VH}$ ) were included in the study.

Data on PD history (age, PD onset, and disease duration) were obtained from all the subjects. All patients were assessed by UPDRS motor scale (subscale III) [10] in on-state. Cognitive impairment was tested by Montreal Cognitive Assessment test (MoCA) [11].

$\mathrm{PDH}+$ subjects were defined as patients with repeated occurrence of $\mathrm{VH}$ either isolated or in combination with other modality hallucinations. Hallucinations were present at study inclusion or have occurred repeatedly in last 2 years and their severity required continuous antipsychotic treatment or significant modification of antiparkinsonian therapy.

VH and delusions were assessed by MDS-UPDRS (Movement Disorder Society-sponsored revision of the Unified Parkinson's Disease Rating Scale), items Hallucinations and psychosis part I [10]. Rush Hallucination Inventory [12, 13] monitored frequency and type (visual, auditory, tactile, and olfactory) of hallucinations.

$\mathrm{PDH}$ - subjects were defined as patients with no history of hallucinations of any type.
Ophthalmological examination included visual acuity $(100 \%$ contrast), intraocular pressure measurement, and fundus examination for exclusion of vitreoretinal pathology. OCT was performed using Zeiss Stratus OCT Model 3000 after pharmacologic pupillary dilatation. Mean RNFL thickness, mean macular thickness apart from fovea, and total macular volume were assessed for both eyes. Results from the eye with higher signal quality were used for statistical analysis.

Contrast sensitivity test, as a parameter of retinal function, was performed in $15 \mathrm{PDH}+$ and $30 \mathrm{PDH}-$ patients. Snellen charts with $2.5 \%$ contrast at a distance of $3 \mathrm{~m}$ were used for testing (Lea Contrast Sensitivity Test) $[14,15]$. The charts were illuminated by $6500 \mathrm{~K}$ light source from a fixed distance.

\section{Statistical Analysis}

Statsoft Statistica 10 software suite was used for analysis. Pearson correlation coefficient, one-sample $t$-test, independent two-sample $t$-test, and dependent $t$-test for paired samples were used. For OCT data also test-retest variability and test for correlation of repeated examination were performed.

For higher statistical significance, 15 pairs of $\mathrm{PDH}+$ and $\mathrm{PDH}-$ matched for age, gender, and disease duration were compared. Control group included 15 healthy subjects in the 6th and 7th decade. Further analysis of results of contrast sensitivity was performed in 8 pairs of patients matched for age, gender, and visual acuity.

\section{Results}

We examined $18 \mathrm{PDH}+$ patients ( 10 men, 8 women) and 34 $\mathrm{PDH}-$ patients (18 men, 16 women). Average age in PDH+ group was 71.8 years and in PDH- group was 68 years. Average duration of the disease in $\mathrm{PDH}+$ group was 10.2 years and in PDH- group 7.5 years. For more details about subjects see Tables 1 and 2. Pure visual hallucinations were present in 16 patients, 1 patient reported both visual and auditory hallucinations, and 1 patient reported both hallucinations and delusions.

Patients with VH had longer disease duration, higher score in motor scale UPDRS, and lower score in MoCA test compared to patients without hallucinations. Differences in other parameters tested (RNFL thickness, macular thickness, and volume) were not statistically significant (Table 3 ). 
TABle 2: Demographic data.

\begin{tabular}{lcccc}
\hline & Paired PDH+ & \multicolumn{2}{c}{ Paired PDH- } & Men \\
& Men & Women & $N=9$ & $N=6$ \\
\hline Mean age (SD) & $N=9$ & $N=6$ & $68.9(6.1)$ & $71.3(4.6)$ \\
Range (years) & $69.9(9.7)$ & $72.5(4.9)$ & $61-78$ & $65-78$ \\
\hline Mean disease duration (SD) & $52-83$ & $65-79$ & $8(3.1)$ & $8.2(4.7)$ \\
Range (years) & $9.3(3.3)$ & $9.5(5.7)$ & $4-13$ & $3-15$ \\
\hline
\end{tabular}

Paired PDH+: paired group of Parkinson's disease with hallucinations; paired PDH-: paired group of Parkinson's disease without hallucinations; SD: standard deviation.

TABLE 3: Two-sample $t$-test for population mean in groups $\mathrm{PDH}+$ and $\mathrm{PDH}-$.

\begin{tabular}{|c|c|c|c|c|}
\hline & $\begin{array}{l}\mathrm{PDH}+ \\
n=18\end{array}$ & $\begin{array}{l}\text { PDH- } \\
n=34\end{array}$ & $\begin{array}{c}t \text {-test } \\
p \text {-value }\end{array}$ & $\begin{array}{c}F \text {-test } \\
p \text {-value }\end{array}$ \\
\hline Age (years) & 71.5 (SD 8.39) & 67.76 (SD 8.24) & 0.13 & 0.89 \\
\hline PD duration (years) & 10.17 (SD 4.45) & 7.12 (SD 4.02) & 0.02 & 0.6 \\
\hline RNFL $(\mu \mathrm{m})$ & 97.9 (SD 10.86) & 97.85 (SD 10.64) & 0.99 & 0.89 \\
\hline Macula $\mathrm{T}(\mu \mathrm{m})$ & 249.96 (SD 18.21) & $252.84(\mathrm{SD} 12.66)$ & 0.51 & 0.07 \\
\hline Macula V $\left(\mathrm{mm}^{3}\right)$ & $6.85(\mathrm{SD} 0.45)$ & $6.89(\mathrm{SD} 0.34)$ & 0.67 & 0.18 \\
\hline UPDRS & 28.06 (SD 9.85) & 16.65 (SD 6.61) & $\mathrm{p}<0.001$ & 0.05 \\
\hline $\mathrm{MoCA}$ & 17.39 (SD 6.58) & 21.35 (SD 3.27) & 0.01 & $p<0.001$ \\
\hline
\end{tabular}

PDH+: Parkinson's disease with hallucinations; PDH-: Parkinson's disease without hallucinations; $n$ : number of patients; SD: standard deviation; RNFL: retinal nerve fiber layer; macula T: macula thickness without fovea; macula V: macula volume; MoCA: Montreal Cognitive Assessment; UPDRS: Unified Parkinson's Disease Rating Scale.

TABLE 4: Paired two-sample $t$-test for population mean in groups $\mathrm{PDH}+$ and $\mathrm{PDH}-$.

\begin{tabular}{|c|c|c|}
\hline & $n=15$ & $\begin{array}{c}t \text {-test } \\
p \text {-value }\end{array}$ \\
\hline $\mathrm{PDH}+$ age (years) & $70.93($ SD 8.02) & \multirow{2}{*}{0.30} \\
\hline PDH- age (years) & 69.87 (SD 5.5) & \\
\hline $\mathrm{PDH}+$ disease duration (years) & $9.4(\mathrm{SD} 4.24)$ & \multirow{2}{*}{0.08} \\
\hline PDH- disease duration (years) & $8.07(\mathrm{SD} 3.67)$ & \\
\hline $\mathrm{PDH}+\mathrm{RNFL}(\mu \mathrm{m})$ & 96.79 (SD 11.11) & \multirow{2}{*}{0.55} \\
\hline PDH- RNFL $(\mu \mathrm{m})$ & $93.94(\mathrm{SD} 12.94)$ & \\
\hline $\mathrm{PDH}+$ macula $\mathrm{T}(\mu \mathrm{m})$ & 248.29 (SD 14.35) & \multirow{2}{*}{0.09} \\
\hline $\mathrm{PDH}-$ macula $\mathrm{T}(\mu \mathrm{m})$ & $256.35(\mathrm{SD} 12.02)$ & \\
\hline $\mathrm{PDH}+$ macula $\mathrm{V}\left(\mathrm{mm}^{3}\right)$ & $6.81(\mathrm{SD} 0.32)$ & \multirow{2}{*}{0.14} \\
\hline PDH- macula V $\left(\mathrm{mm}^{3}\right)$ & $6.99(\mathrm{SD} 0.32)$ & \\
\hline $\mathrm{PDH}+\mathrm{UPDRS}$ & 27.33 (SD 10.03) & \multirow{2}{*}{$\mathrm{p}<0.0001$} \\
\hline PDH- UPDRS & $14.4(\mathrm{SD} 5.37)$ & \\
\hline $\mathrm{PDH}+\mathrm{MoCA}$ & $18.4(\mathrm{SD} 6.65)$ & \multirow{2}{*}{0.19} \\
\hline PDH- MoCA & 21.47 (SD 3.31) & \\
\hline
\end{tabular}

PDH+: Parkinson's disease with hallucinations; PDH-: Parkinson's disease without hallucinations; $n$ : number of paired patients; SD: standard deviation; RNFL: retinal nerve fiber layer; macula T: macula thickness without fovea; macula V: macula volume; MoCA: Montreal Cognitive Assessment; UPDRS: Unified Parkinson's Disease Rating Scale.

When analyzing the 15 pairs of $\mathrm{PDH}+$ and $\mathrm{PDH}-$ matched for age, gender, and disease duration, the UPDRS score was higher $(p<0.0001)$ in PDH+. There was no significant difference in other parameters (RNFL thickness, macular thickness, macular volume, and MoCA score) (Table 4).
There was no significant difference in low contrast vision (2.5\% contrast test) between $\mathrm{PDH}+$ and $\mathrm{PDH}-$ patients matched for age and gender (test was available for 8 pairs). Mean value of $2.5 \%$ contrast sensitivity was 0.39 (SD 0.2) in $\mathrm{PDH}+$ and 0.23 (SD 0.21) in PDH- $(p=0.23)$, CI $(-0.13$; $0.46)$. 
TABLE 5: Comparison of groups of patients with PD and healthy persons in range of age 60 to 69 and 70 to 79 years. Unpaired two-sample $t$-test.

(a)

\begin{tabular}{|c|c|c|c|c|}
\hline $60-69$ years & $\begin{array}{c}\mathrm{PD} \\
n=26\end{array}$ & $\begin{array}{l}\text { Healthy controls } \\
\qquad n=8\end{array}$ & $\begin{array}{c}t \text {-test } \\
p \text {-value }\end{array}$ & $\begin{array}{c}F \text {-test } \\
p \text {-value }\end{array}$ \\
\hline RNFL $(\mu \mathrm{m})$ & $\begin{array}{c}102.4 \\
(\mathrm{SD} 10.55)\end{array}$ & $\begin{array}{c}97.22 \\
(\mathrm{SD} 6.54)\end{array}$ & 0.20 & 0.19 \\
\hline Macula $\mathrm{T}(\mu \mathrm{m})$ & $\begin{array}{c}256.71 \\
(\mathrm{SD} 16.31) \\
\end{array}$ & $\begin{array}{c}252.56 \\
(\mathrm{SD} 13.98) \\
\end{array}$ & 0.52 & 0.71 \\
\hline Macula V $\left(\mathrm{mm}^{3}\right)$ & $\begin{array}{c}6.98 \\
(S D 0.43)\end{array}$ & $\begin{array}{c}6.86 \\
(\mathrm{SD} 0.37)\end{array}$ & 0.47 & 0.70 \\
\hline
\end{tabular}

(b)

\begin{tabular}{|c|c|c|c|c|}
\hline $70-79$ years & $\begin{array}{c}\mathrm{PD} \\
n=18\end{array}$ & $\begin{array}{l}\text { Healthy controls } \\
\qquad n=7\end{array}$ & $\begin{array}{c}t \text {-test } \\
p \text {-value }\end{array}$ & $\begin{array}{c}F \text {-test } \\
p \text {-value }\end{array}$ \\
\hline RNFL $(\mu \mathrm{m})$ & $\begin{array}{c}91.33 \\
(\mathrm{SD} 6.34) \\
\end{array}$ & $\begin{array}{c}93.35 \\
(\mathrm{SD} 9.71) \\
\end{array}$ & 0.54 & 0.16 \\
\hline Macula $\mathrm{T}(\mu \mathrm{m})$ & $\begin{array}{c}247.48 \\
(\mathrm{SD} 11.86)\end{array}$ & $\begin{array}{c}249.84 \\
(\mathrm{SD} 4.41)\end{array}$ & 0.68 & 0.49 \\
\hline
\end{tabular}

PD: Parkinson's disease; SD: standard deviation; $n$ : number of patients; RNFL: retinal nerve fiber layer; macula T: macula thickness without fovea; macula V: macula volume.

(c)

\begin{tabular}{|c|c|c|c|c|}
\hline $60-79$ years & $\begin{array}{c}\text { PD } \\
n=44\end{array}$ & $\begin{array}{l}\text { Healthy controls } \\
\qquad n=15\end{array}$ & $\begin{array}{c}t \text {-test } \\
p \text {-value }\end{array}$ & $\begin{array}{c}F \text {-test } \\
p \text {-value }\end{array}$ \\
\hline RNFL $(\mu \mathrm{m})$ & $\begin{array}{c}97.87 \\
(\mathrm{SD} 10.53)\end{array}$ & $\begin{array}{c}95.42 \\
(\mathrm{SD} 8.11)\end{array}$ & 0.41 & 0.29 \\
\hline Macula $\mathrm{T}(\mu \mathrm{m})$ & $\begin{array}{c}252.93 \\
(\mathrm{SD} 15.21) \\
\end{array}$ & $\begin{array}{c}252.29 \\
(\mathrm{SD} 13.74) \\
\end{array}$ & 0.71 & 0.70 \\
\hline Macula V $\left(\mathrm{mm}^{3}\right)$ & $\begin{array}{c}6.91 \\
(\mathrm{SD} 0.38)\end{array}$ & $\begin{array}{c}6.82 \\
(\mathrm{SD} 0.36)\end{array}$ & 0.43 & 0.83 \\
\hline
\end{tabular}

Note: as the age and observed RNFL and macula parameters exhibit the same correlation in all groups, we decided to join the age groups (initially observed by decades) together and perform the statistics on larger samples. For all the tested parameters the $p$-values are significantly more than critical level of 0.05 ; that is, no statistically significant difference was found in the samples.

There was no significant difference in RNFL thickness, macular thickness, and macular volume between PD and normal control group ( $p>0.05$ for all $p$-values) (Table 5).

\section{Discussion}

It has been shown in several studies that patients with PD have lower RNFL thickness, macular thickness, and macular volume than normal controls [16-21] (Table 6). However, other studies with OCT failed to find significant difference between PD patients and healthy subjects [22, 23].

Controversial results may be predetermined by subject selection, small sample sizes, or variable sensitivity of OCT instruments.

The very first OCT study investigating VH in PD patients, Lee et al. [24] (with mean age and PD duration similar to our study), used high-resolution spectral domain OCT for comparison of $56 \mathrm{PD}$ patients in three subgroups: no $\mathrm{VH}$ and no dementia (VH-D-), with $\mathrm{VH}$ and no dementia $(\mathrm{VH}+\mathrm{D}-)$, and with $\mathrm{VH}$ and with dementia $(\mathrm{VH}+\mathrm{D}+)$ to
30 healthy controls. The RNFL was thinnest in the group $\mathrm{VH}+\mathrm{D}-$, followed by the group $\mathrm{VH}+\mathrm{D}+$, and the group $\mathrm{VH}-\mathrm{D}-$.

Our results did not show any significant difference in RNFL thickness and macular thickness and volume, neither between $\mathrm{PDH}+$ and $\mathrm{PDH}-$ subgroups nor between 15 matched pairs of $\mathrm{PDH}+$ and $\mathrm{PDH}-$. No significant difference was found between patients and healthy controls matched by age and gender.

In our study, mean age in PD subjects was higher than in studies that reported difference between PD and control groups [16, 18-20]. Younger patients with shorter disease duration may have different results than a group of older patients or a group of patients with longer duration of PD or cohorts with uneven proportion of disease stages. In addition, retinal thickness differs between male and female subjects of the same age.

If structural changes of retina, as a consequence of neurodegeneration, are present since the early stages of PD, such changes should persist or progress in time. According 
TABLE 6

\begin{tabular}{|c|c|c|c|c|c|}
\hline Author & $\begin{array}{c}\text { Number of } \\
\text { patients with PN }\end{array}$ & $\begin{array}{l}\text { Number of } \\
\text { controls }\end{array}$ & Results & $p$-value & OCT device \\
\hline $\begin{array}{l}\text { Inzelberg et } \\
\text { al. } 2004[18]\end{array}$ & 10 & 10 & $\begin{array}{l}\text { Thinning of peripapillar RNFL } \\
\text { thickness in the inferotemporal area }\end{array}$ & 0.0003 & Not mentioned \\
\hline $\begin{array}{l}\text { Altintaş et al. } \\
2008[16]\end{array}$ & 17 & 11 & $\begin{array}{l}\text { Thinning of RNFL thickness and } \\
\text { reduce of macula volume }\end{array}$ & $<0.05$ & $\begin{array}{l}\text { OCT model } 3000 \\
\text { software version A1.1 }\end{array}$ \\
\hline $\begin{array}{l}\text { Hajee et al. } \\
2009[17]\end{array}$ & 23 & 17 & $\begin{array}{l}\text { Thinning of paramacular inner } \\
\text { retinal layer }\end{array}$ & 0.01 & Fourier-domain OCT \\
\hline $\begin{array}{l}\text { Moschos et } \\
\text { al. } 2011[20]\end{array}$ & 16 & 20 & $\begin{array}{l}\text { Thinning of RNFL thickness in the } \\
\text { inferior and temporal area }\end{array}$ & $<0.0001$ and 0.0045 & $\begin{array}{l}\text { OCT Stratus Model } \\
3000\end{array}$ \\
\hline $\begin{array}{l}\text { Kirbas et al. } \\
2013[19]\end{array}$ & 42 & 40 & $\begin{array}{l}\text { Thinning of RNFL thickness in the } \\
\text { temporal quadrant }\end{array}$ & 0.001 & Cirrus HD SD-OCT \\
\hline $\begin{array}{l}\text { Morgia et al. } \\
2013[21]\end{array}$ & 41 & 86 & $\begin{array}{l}\text { Thinning of RNFL layer in the } \\
\text { temporal quadrant }\end{array}$ & 0.004 & $\begin{array}{l}\text { Stratus OCT software } \\
\text { version } 4.0 .1\end{array}$ \\
\hline
\end{tabular}

OCT: optical coherence tomography; PN: Parkinson’s disease; RNFL: retinal nerve fiber layer.

to our knowledge, such prospective longitudinal studies are missing.

Reduced contrast sensitivity in PD patients compared to controls has been reported in several studies $[14,15$, 25]. In our study, no significant difference at $2.5 \%$ contrast sensitivity test was found between $\mathrm{PDH}+$ and $\mathrm{PDH}-$ groups. Incidence of hallucinations was not related to values of $2.5 \%$ contrast sensitivity test. We conclude that contrast sensitivity, a parameter of retinal function, plays no role in the incidence of hallucinations in $\mathrm{PD}$. This finding correlates with the results of morphological parameters tested by OCT where no significant difference was found between $\mathrm{PDH}+$ and $\mathrm{PDH}-$ groups. Structural and functional parameters were in concordance.

Analysis of $\mathrm{PDH}+$ patients revealed significantly longer disease duration, higher score in UPDRS, and lower score in MoCA compared with PDH- group. Incidence of hallucinations thus increases with disease duration. In analysis of pairs of $\mathrm{PDH}+$ and $\mathrm{PDH}-$ patients we found significantly higher score in UPDRS in PDH+ subjects compared with PDH-. Patients with hallucinations had more severe motor impairment than PD subjects of same age, gender, and disease duration without hallucinations. Risk of hallucinations is therefore greater in patients with more severe motor impairment. Cognitive decline showed no influence on presence of hallucinations.

Our data show that patients with and without VH cannot be distinguished by means of OCT. No morphological or functional changes of retina were found in $\mathrm{PDH}+$ in comparison with PDH-. This can be explained by several factors. We can presume that occurrence of $\mathrm{VH}$ is underlined by morphological or functional changes at cerebral level and does not relate to retina. Or we can speculate that $\mathrm{VH}$ are related to complex dysfunction on retinal level but is not represented by total retinal thinning chosen as an outcome in this study.

The strength of the study is a rigorous matching by age, gender, and disease duration, which creates homogeneous cohorts.
Our conclusion is further supported by no difference in low contrast sensitivity testing between $\mathrm{PDH}+$ and $\mathrm{PDH}-$ subgroups. According to our results, we also infer that presence of $\mathrm{VH}$ may not be primarily related to cognitive decline.

\section{Conclusion}

Besides recently published study of Lee at al. [24], this is the only study dealing with structural and functional parameters of retina in PD patients with and without VH. Neither structural parameters of retina tested by means of OCT nor contrast sensitivity as a functional measure differ between PD patients with $\mathrm{VH}$ and without $\mathrm{VH}$.

We conclude that functional and structural changes in retina are not related to $\mathrm{VH}$ in $\mathrm{PD}$.

Further studies should focus on possible changes in segmented layers of retina, specifically in a layer with amacrine cells.

\section{Conflict of Interests}

The authors declare that there is no conflict of interests regarding the publication of this paper.

\section{Acknowledgments}

This is paper is supported by the Czech Ministry of Education, PRVOUK-P26/LF1/4, and by IGA MZCR Grant NT13239-4.

\section{References}

[1] K. A. Jellinger, "Neuropathology of sporadic Parkinson's disease: evaluation and changes of concepts," Movement Disorders, vol. 27, no. 1, pp. 8-30, 2012.

[2] C. G. Goetz, G. T. Stebbins, and B. Ouyang, "Visual plus nonvisual hallucinations in Parkinson's disease: development 
and evolution over 10 years," Movement Disorders, vol. 26, no. 12, pp. 2196-2200, 2011.

[3] P. Huot, T. H. Johnston, T. Darr et al., "Increased 5- $\mathrm{HT}_{2 \mathrm{~A}}$ receptors in the temporal cortex of Parkinsonian patients with visual hallucinations," Movement Disorders, vol. 25, no. 10, pp. 1399-1408, 2010.

[4] J. Barnes and A. S. David, "Visual hallucinations in Parkinson's disease: a review and phenomenological survey," Journal of Neurology Neurosurgery and Psychiatry, vol. 70, no. 6, pp. 727733, 2001.

[5] E. Gleason, "The influences of metabotropic receptor activation on cellular signaling and synaptic function in amacrine cells," Visual Neuroscience, vol. 29, no. 1, pp. 31-39, 2012.

[6] N. K. Archibald, M. P. Clarke, U. P. Mosimann, and D. J. Burn, "The retina in Parkinsons disease," Brain, vol. 132, no. 5, pp. 1128-1145, 2009.

[7] G. Fénelon, F. Mahieux, R. Huon, and M. Ziégler, "Hallucinations in Parkinson's disease. Prevalence, phenomenology and risk factors," Brain, vol. 123, no. 4, pp. 733-745, 2000.

[8] T. Tian, X.-H. Zhu, and Y.-H. Liu, "Potential role of retina as a biomarker for progression of Parkinson's disease," International Journal of Ophthalmology, vol. 4, no. 4, pp. 433-438, 2011.

[9] D. J. Gelb, E. Oliver, and S. Gilman, "Diagnostic criteria for Parkinson's disease," Archives of Neurology, vol. 56, no. 1, pp. 3339, 1999.

[10] C. G. Goetz, B. C. Tilley, S. R. Shaftman et al., "Movement Disorder Society-Sponsored Revision of the Unified Parkinson's Disease Rating Scale (MDS-UPDRS): scale presentation and clinimetric testing results," Movement Disorders, vol. 23, no. 15, pp. 2129-2170, 2008.

[11] D. J. Gill, A. Freshman, J. A. Blender, and B. Ravina, "The Montreal cognitive assessment as a screening tool for cognitive impairment in Parkinson's disease," Movement Disorders, vol. 23, no. 7, pp. 1043-1046, 2008.

[12] C. G. Goetz, S. Leurgans, E. J. Pappert, R. Raman, and A. B. Stemer, "Prospective longitudinal assessment of hallucinations in Parkinson's disease," Neurology, vol. 57, no. 11, pp. 2078-2082, 2001.

[13] C. G. Goetz, B. Ouyang, A. Negron, and G. T. Stebbins, "Hallucinations and sleep disorders in PD: ten-year prospective longitudinal study," Neurology, vol. 75, no. 20, pp. 1773-1779, 2010.

[14] V. Pieri, N. J. Diederich, R. Raman, and C. G. Goetz, "Decreased color discrimination and contrast sensitivity in Parkinson's disease," Journal of the Neurological Sciences, vol. 172, no. 1, pp. 7-11, 2000.

[15] M. J. Price, R. G. Feldman, D. Adelberg, and H. Kayne, "Abnormalities in color vision and contrast sensitivity in Parkinson's disease," Neurology, vol. 42, no. 4, pp. 887-890, 1992.

[16] Ö. Altintaş, P. Işeri, B. Özkan, and Y. Cağlar, "Correlation between retinal morphological and functional findings and clinical severity in Parkinson's disease," Documenta Ophthalmologica, vol. 116, no. 2, pp. 137-146, 2008.

[17] M. E. Hajee, W. F. March, D. R. Lazzaro et al., "Inner retinal layer thinning in Parkinson disease," Archives of Ophthalmology, vol. 127, no. 6, pp. 737-741, 2009.

[18] R. Inzelberg, J. A. Ramirez, P. Nisipeanu, and A. Ophir, "Retinal nerve fiber layer thinning in Parkinson disease," Vision Research, vol. 44, no. 24, pp. 2793-2797, 2004.

[19] S. Kirbas, K. Turkyilmaz, A. Tufekci, and M. Durmus, "Retinal nerve fiber layer thickness in parkinson disease," Journal of Neuro-Ophthalmology, vol. 33, no. 1, pp. 62-65, 2013.
[20] M. M. Moschos, G. Tagaris, I. Markopoulos et al., "Morphologic changes and functional retinal impairment in patients with Parkinson disease without visual loss," European Journal of Ophthalmology, vol. 21, no. 1, pp. 24-29, 2011.

[21] C. A. Morgia, P. Barboni, G. Rizzo et al., "Loss of temporal retinal nerve fibers in Parkinson disease: a mitochondrial pattern?" European Journal of Neurology, vol. 20, no. 1, pp. 198201, 2013.

[22] G. D. Aaker, J. S. Myung, J. R. Ehrlich, M. Mohammed, C. Henchcliffe, and S. Kiss, "Detection of retinal changes in Parkinson's disease with spectral-domain optical coherence tomography," Clinical Ophthalmology, vol. 4, no. 1, pp. 14271432, 2010.

[23] N. K. Archibald, M. P. Clarke, U. P. Mosimann, and D. J. Burn, "Retinal thickness in Parkinson's disease," Parkinsonism and Related Disorders, vol. 17, no. 6, pp. 431-436, 2011.

[24] J.-Y. Lee, J. M. Kim, J. Ahn, H.-J. Kim, B. S. Jeon, and T. W. Kim, "Retinal nerve fiber layer thickness and visual hallucinations in Parkinson's Disease," Movement Disorders, vol. 29, no. 1, pp. 6167, 2014.

[25] C. R. Adam, E. Shrier, Y. Ding, S. Glazman, and I. BodisWollner, "Correlation of inner retinal thickness evaluated by spectral-domain optical coherence tomography and contrast sensitivity in Parkinson disease," Journal of NeuroOphthalmology, vol. 33, no. 2, pp. 137-142, 2013. 


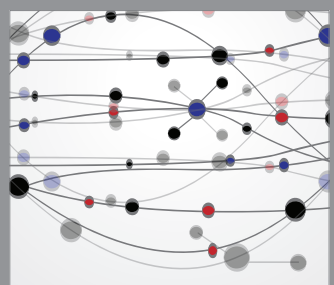

The Scientific World Journal
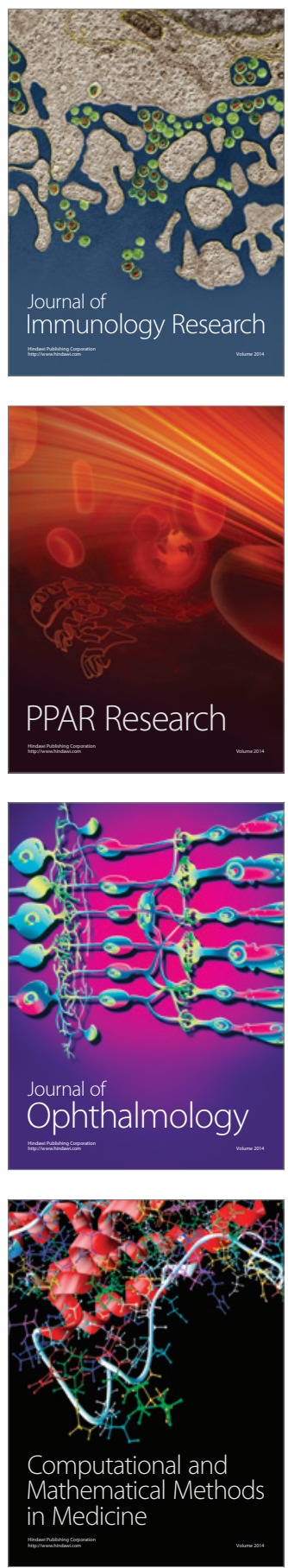

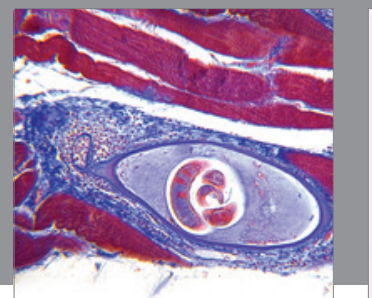

Gastroenterology

Research and Practice
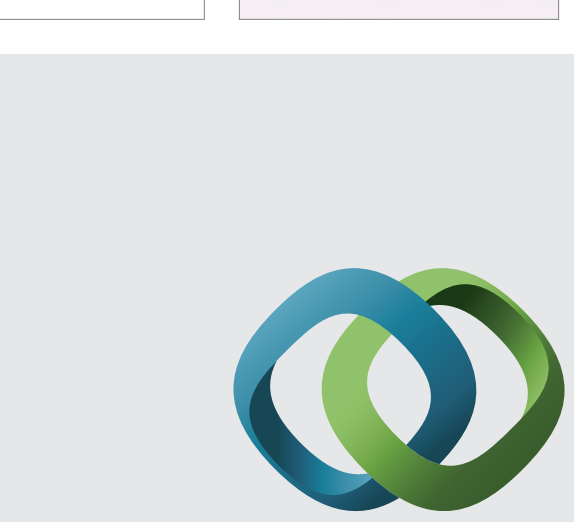

\section{Hindawi}

Submit your manuscripts at

http://www.hindawi.com
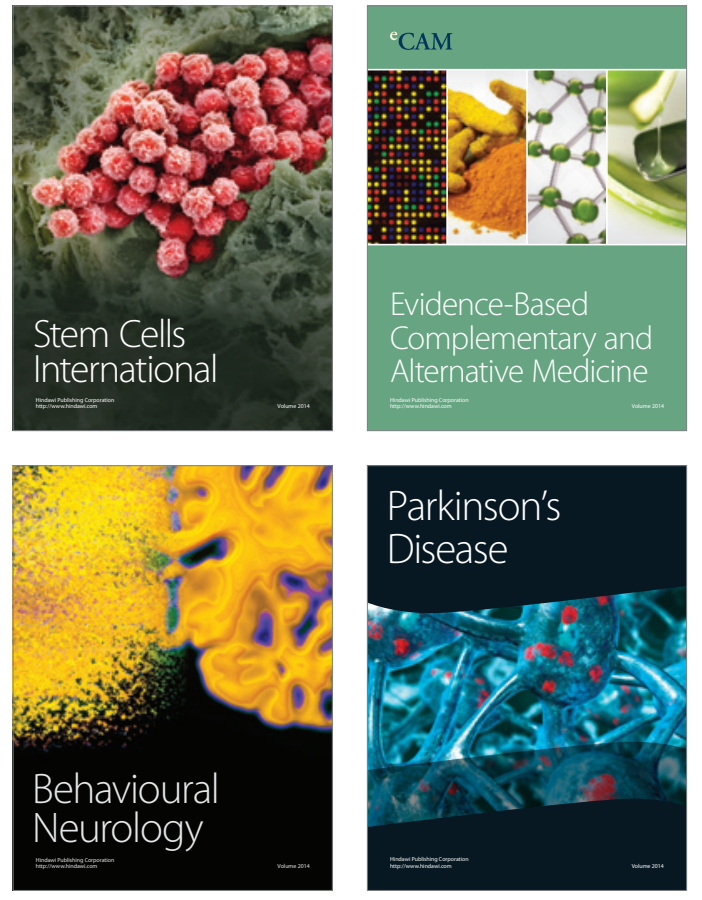
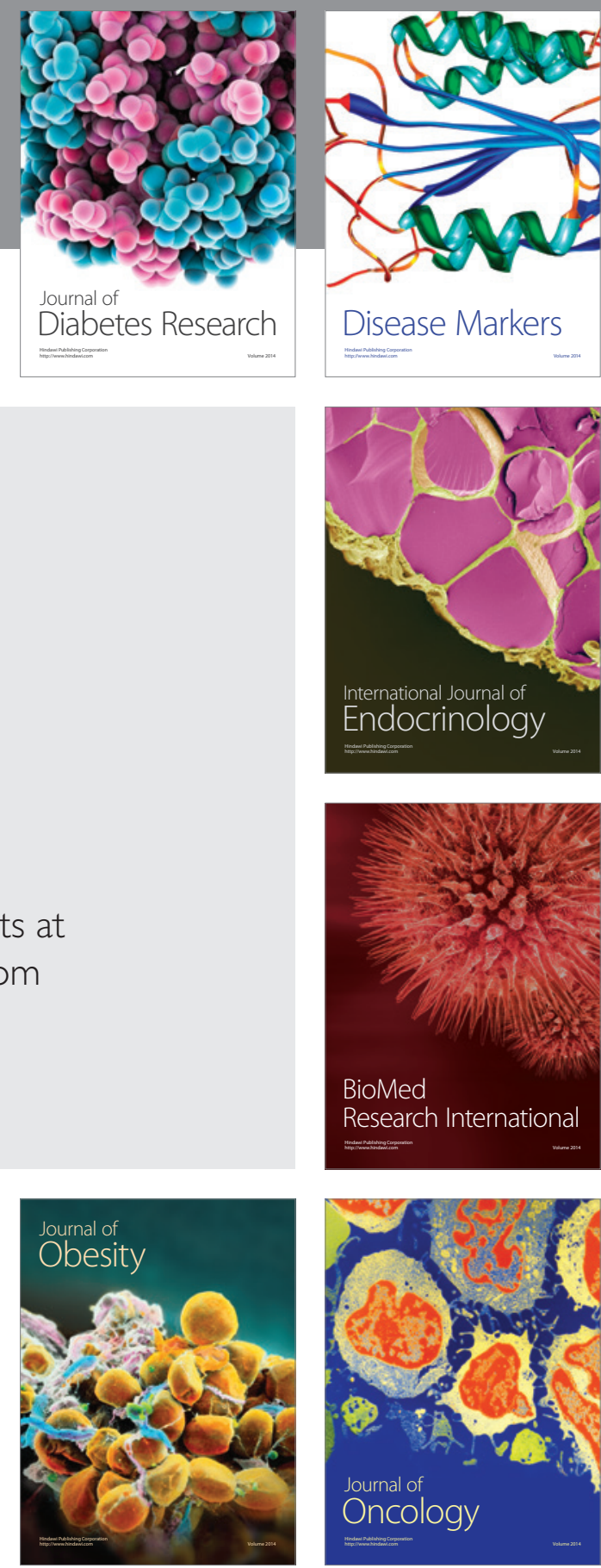

Disease Markers
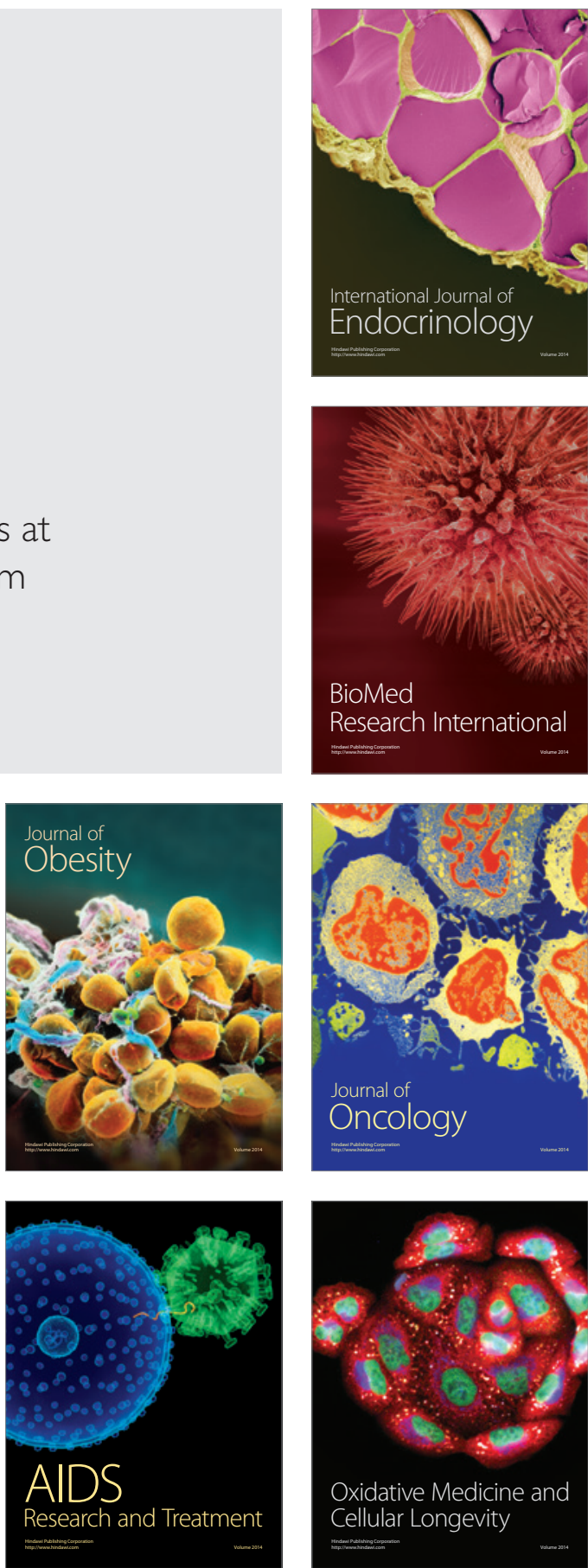